\title{
Demographic and Personal Characteristics Associated with Exclusive Breastfeeding among Lactating Mother in Siaya County of Nyanza Province in Kenya
}

\author{
Samuel Jerry Odindo ${ }^{1, *}$, Dan O. Odindo ${ }^{2}$, John Alwar $^{3}$, Rose Olayo ${ }^{4}$, Aaron Mwayi ${ }^{4}$, Henry Oyugi $^{5}$ \\ ${ }^{1}$ Department of Health System Management, Great Lakes University of Kisumu, 40100, Kenya \\ ${ }^{2}$ Department of Health System Management, Great Lakes University of Kisumu, Kisumu, 401002224 , Kenya \\ ${ }^{3}$ Department of combating ill health, Great Lakes University of Kisumu, 40100 2224, Kenya \\ ${ }^{4}$ Department of Health Promotion, Great Lakes University of Kisumu, 40100 2224, Kenya \\ ${ }^{5}$ Department of Measurement, Great Lakes University of Kisumu, 40100, 2224, Kenya \\ *Corresponding Author: kabokasam@gmail.com
}

Copyright $(\underset{C}{ } 2014$ Horizon Research Publishing All rights reserved.

\begin{abstract}
Introduction: This was a nested study in which 2011 data from a baseline study conducted by Great Lakes University of Kisumu, supported with funds from UNICEF Kenya, findings was analyzed and used to assess the role of demographic and personal characteristic associated with exclusive breast feeding as a way of checking the high mortality of under-5 children in Nyanza province. Methods: A multi-stage cluster sampling technique was used to select 3,200 households. Descriptive statistics were used to determine the coverage of exclusive breastfeeding practice. Frequencies were run using SPSS and Chi -square test was used to determine the association. Findings: The practice of exclusive breastfeeding in Siaya County is found at 29.9\%; with unemployed mothers presenting at $36.1 \%$, while working class mothers performed poorly at $21.4 \%$. On demographic factors, marital status reported that polygamous had $33.0 \%$. Single mothers reported $36.0 \%$.On personal characteristics, the time taken to initiate breast milk to a baby had an association with exclusive breast feeding. Conclusion: Marital status, putting the child on breast milk has an association with exclusive breastfeeding.
\end{abstract}

Keywords Exclusive Breast Feeding, Maternal Health, Under Five, Demographic and Personal Characteristics

\section{Introduction}

More than 10 million children under the age of five die each year ${ }^{4}, 41 \%$ of the deaths occur in the Sub - Saharan Africa and $34 \%$ in South Asia. A major cause of death is inappropriate breastfeeding practices that complicate frequent infections ${ }^{3}$. According to WHO, 1.5 million deaths are caused by lack of immediate or exclusive breastfeeding in infancy ${ }^{13}$. The widely accepted "universal coverage" target for exclusive breast feeding is $90 \%{ }^{[5]}$. The $32 \%$ prevalence of exclusive breast feeding in Kenya falls below the widely accepted "universal coverage" target for exclusive breast feeding at $90 \%{ }^{[6]}$.

In African families, fathers play a strong role in the decision of whether or not; to breastfeed. Fathers may be opposed to breastfeeding because of concerns about what their role would be in feeding, whether they would be able to bond with their infant if they were personally unable to feed the baby, and how the mother would be able to accomplish household responsibilities if she breastfed ${ }^{[9]}$.

Studies of African American families in which education on breastfeeding was directed at the father, found a 20 percent increase in breastfeeding rates, indicating that paternal influences on maternal feeding practices are critically important in early decision making about breastfeeding ${ }^{[14]}$.

In Africa, as noted, clinics and health centres advise mothers to breastfeed exclusively for at least the first six months of their babies' lives. However, when mothers arrive home, several other factors come into play. First, in the African context, mothers are usually not the sole decision makers when it comes to their children. Grandmothers play an important role in the mothers' and infants' lives and are said to have a strong influence over what mothers feed their babies.

Low levels of involvement by fathers and other community members in infant care is another reason for not taking the advice from health centres easily. The absence of men and youth groups from infants breastfeeding promotion activities has been identified as a contributing factor to the low numbers of women who breastfeed ${ }^{[14]}$.

\subsection{Objective}

1. To examine demographic factors associated with exclusive breast feeding practices among lactating mothers in Siaya County. 
2. To determine personal characteristics associated with exclusive breast feeding practices among lactating mothers in Siaya County.

\section{Methodology}

\subsection{Study Design}

This was a descriptive designed in which quantitative secondary data from the baseline Survey was analysed.

\subsection{Study Site}

The survey was done by GLUK/ UNICEF in Homabay and Siaya county, in the month of September, 2011 though the key focus for this study is Siaya County in which 5 districts are covered, that is Bondo, Rarieda, Gem, Ugunja and Ugenya.

\subsection{Study Population}

This study targeted households with women of reproductive age (15-49) and have children who are under five years old.

The target population for this study was the women of reproductive age (15-49) who had children under the age of five years. The unit of observation was a woman of reproductive age $(15-49)$ and stays in the households, because she was the key focus of the study.

\subsection{Unit of Analysis}

The unit of analysis targeted lactating mothers with infants less than 5 years old, and who had previously breastfed their baby during their age of six month below in Siaya County.

\subsection{Sample Design and Sample Size}

The data used from the study is based from baseline survey conducted in October November 2011 in which the multistage probability sampling design was used. The sample size drawn from the study was 2,805 households. My study is pegged on exclusive breast feeding mothers whom have to be drawn from the same data set.

\subsection{Inclusion Criteria}

Households with infants under the age of 5 years old preceding the survey were eligible for the study.

\subsection{Exclusion Criteria}

The study excluded households who did not have children under the age of five years old prior to the study.

\subsection{Data Processing}

Immediately after field work, data was entered on daily basis by the data clerks. Consistency and completeness checks were done and data cleaned. Information from the questionnaires was electronically entered using Statistical Package for Social Sciences (SPSS) version 16 programme. All the hard copies of all questionnaires were used for counter checking the information electronically entered. Each tool was entered individually and no merging was done during the entry.

\subsection{Data Analysis}

This was a quantitative research study in which the unit of analysis was mothers with infants less than 5 years old and had previously breastfed their baby during their age of six month below in Siaya County.

Out of this 2,805, my study only included households with mothers in the age category of 15 to 49 and is having infants under the age of five years and excluded households who did not have children under the age of five years and therefore, my denominator for my study was 1815 .

The descriptive statistics were used to determine the prevalence of exclusive breast feeding practice in which frequencies were run using SPSS.

Chi-square test was used for both objectives. The p.value $(p=0.001)$ is used to show the test statistic if it's significant at the $5 \%$ level. In objective $4,2 \times 2$ contingencies tables for categorical variables was used to find the odd ratio in ANC and Health facility delivery which have two categories.

\section{Results}

\subsection{Demographic Factors Associated with Exclusive Breast Feeding Practice}

My finding shows that polygamous mother's breastfeed more than the monogamous mothers. 33.0\%(32/97) married (polygamous) respondents $29.7 \% \quad(420 / 1413)$ married (monogamous) respondents. Single mothers reported the highest rate of exclusive breast feeding at 36.0\% (71/197). The $p$-value $(p=0.001)$ shows the chi square test is significant at the $5 \%$ level. The study shows that there is association between Marital Status and Exclusive Breastfeeding. ( $p=0.001)$.

\subsection{Personal Characteristics and Association with Exclusive Breast Feeding Practice}

ANC attendance, Health facility delivery, counseling and referral of food by prescription recorded almost the same rate at $29 \%$ with no association with exclusive breastfeeding. $97.5 \%$ of the mothers with under 5 , attended ANC. Out of this $97.5 \%, 29.9 \%$ practice exclusive breastfeeding. $2.5 \%$ did not attend ANC, and out of this, $28.9 \%$ practice exclusive breastfeeding. Out of all the mothers with under five interviewed, $63.4 \%$ attended health facility and out of this, $29.6 \%$ practice exclusive breastfeeding. $36.6 \%$ did not attend health facility delivery and $30.4 \%$ practice exclusive breastfeeding. Those who did not attend ANC attendance 
and health facility delivery recorded low percentage that relate to almost the same percentage of exclusive breastfeeding with ANC attendance and health facility delivery. When putting the child on breast milk, my findings reveals that there is an association between the time of putting the child on breast milk and exclusive breastfeeding. The $p$-value $(p=0.019)$ shows the chi square test is significant at $5 \%$ level. The study shows that there is an association between the time of putting the child on breast milk and exclusive breast feeding.

Table 1. Demographic factors and association with exclusive breastfeeding.

\begin{tabular}{|c|c|c|c|}
\hline & $\begin{array}{c}\text { Overall }(\mathrm{N}=1815) \\
\%(\mathrm{n})\end{array}$ & $\begin{array}{c}\text { Exclusive Breastfeeding } \\
\%\end{array}$ & P-Value \\
\hline $\begin{array}{c}\text { Marital Status } \\
\text { Married (Monogamy) } \\
\text { Married (Polygamy) } \\
\text { Widow (er) } \\
\text { Separated/Divorced } \\
\text { Single } \\
\end{array}$ & $\begin{aligned} & 77.9(1413) \\
& 5.3(97) \\
& 5.0(91) \\
& 0.9(17) \\
& 10.9(197) \\
&\end{aligned}$ & $\begin{array}{cc}29.7 & (1413) \\
33.0 & (97) \\
16.5 & (91) \\
17.6 & (17) \\
36.0 & (197) \\
\end{array}$ & 0.001 \\
\hline 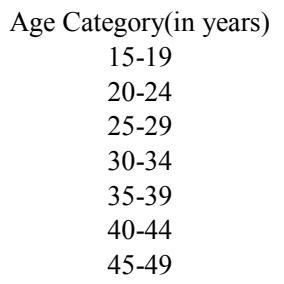 & $\begin{aligned} 3.5 & (63) \\
9.9 & (179) \\
3.1 & (57) \\
15.2 & (276) \\
24.1 & (437) \\
32.9 & (597) \\
11.3 & (206)\end{aligned}$ & $\begin{array}{cc}15.9 & (63) \\
20.1 & (179) \\
21.1 & (57) \\
26.4 & (276) \\
27.2 & (437) \\
34.8 & (597) \\
40.8 & (206)\end{array}$ & 0.001 \\
\hline
\end{tabular}

Table 2. Personal characteristics and association with exclusive breast feeding practice

\begin{tabular}{|c|c|c|c|c|}
\hline & $\begin{array}{l}\text { Overall( } \mathrm{N}=1815) \\
\% \quad(\mathrm{n})\end{array}$ & $\begin{array}{c}\text { Exclusive Breastfeeding } \\
\% \quad \text { (n) }\end{array}$ & P-Value & $\begin{array}{c}\text { Odd Ratio } \\
(95 \quad \mathrm{CI}) \\
\text { OR }(<95 \mathrm{CI}>)\end{array}$ \\
\hline $\begin{array}{c}\text { ANC attendance } \\
\text { Yes } \\
\text { No } \\
\end{array}$ & $\begin{array}{l}97.5(1770) \\
2.5 \quad(45) \\
\end{array}$ & $\begin{array}{cc}29.9(1770) \\
28.9(45) \\
\end{array}$ & 0.885 & $1.049(0.546<\mathrm{CI}<2.015)$ \\
\hline $\begin{array}{l}\text { Health facility delivery } \\
\qquad \begin{array}{c}\text { Yes } \\
\text { No }\end{array}\end{array}$ & $\begin{array}{cc}63.4 & (1151) \\
36.6 & (664)\end{array}$ & $\begin{array}{cc}29.6 & (1151) \\
30.4 \quad(664)\end{array}$ & 0.722 & $\begin{array}{c}0.963 \\
(0.782<\mathrm{CI}<1.186)\end{array}$ \\
\hline $\begin{array}{l}\text { Put the Child on the } \\
\text { Breast } \\
\text { Immediately } \\
\text { After the first hour } \\
\text { After one day } \\
\text { After more than one } \\
\text { day }\end{array}$ & $\begin{array}{cc}57.4 & (1041) \\
33.6 & (609) \\
7.0 & (128) \\
2.0 & (37)\end{array}$ & $\begin{array}{cc}30.9 & (1041) \\
26.1 & (609) \\
39.1 & (128) \\
32.4 & (37)\end{array}$ & 0.019 & N/A \\
\hline $\begin{array}{c}\text { Counselling } \\
\text { Yes } \\
\text { No } \\
\text { Can't remember }\end{array}$ & $\begin{aligned} 68.3 & (1239) \\
30.2 & (549) \\
1.5 & (27)\end{aligned}$ & $\begin{array}{cc}29.5 & (1239) \\
30.6 & (549) \\
29.6 & (27)\end{array}$ & 0.728 & N/A \\
\hline $\begin{array}{c}\text { Referral of food by } \\
\text { prescription. } \\
\text { Yes } \\
\text { No } \\
\text { Can't remember }\end{array}$ & $\begin{array}{cl}31.6 & (573) \\
66.7 & (1211) \\
1.7 & (31)\end{array}$ & $\begin{array}{cc}29.1 & (573) \\
30.4 & (1211) \\
25.8 & (31)\end{array}$ & 0.763 & N/A \\
\hline
\end{tabular}




\section{Discussion}

\subsection{Demographic Factors Associated with Exclusive Breast Feeding Practices among Lactating Mothers in Siaya County}

The finding of this study has revealed that marital status was significantly associated with exclusive breastfeeding. Age of the mother was also associated with breastfeeding. The older the woman the more she is likely to practice breastfeeding. This finding agrees with finding of a previous study by Dennis eta al, who reported that women who are older ( $>25$ years) are more likely to initiate and continue breastfeeding compared to younger women (Dennis, 2002b; Ertem et al., 2001; Scott and JayalakshmiVelpuri 2004). Another research study published between 1980 and 1999 indicated that only $9.1 \%$ of mothers younger than 20 years of age continued to breastfeed to six months, whereas women who were older were more likely (15-34) to have breastfed for six months.

These findings disagree with the report by the 2005 Ethiopian Demographic and Health Survey (EDHS) that was conducted on a nationally representative sample of the nine regions and two city administrations of the country reveals that there is no association in maternal age with exclusive breast feeding. However the study design and sample sizes would have played a role for the difference in associations in the finding.

On the marital status of the breastfeeding mother, the research finding reveals that there is an association on marital status and exclusive breast feeding. This finding in association agrees with the study done by Comfort, MPH class of 2011 in Ethiopia which reports that there is an association of maternal status with exclusive breast feeding. The difference in this research finding reveals that women who are not currently married were two times more likely to breast feed their child exclusively than those married. It also agrees with the findings by Kok 2001, report that in Malaysia, the same study on association of marital status and exclusive breast feeding reveals that mothers with supportive husbands on breastfeeding were 4 times more likely to exclusively breastfeed compared to non-supportive husbands. The research findings have given a vague verification on this two research findings by sub grouping the marital status on monogamous, polygamous, divorce, widow and single. Single mothers have reported a high rate of exclusive breast feeding than the married monogamous mothers. The rate is higher than the one of the divorce and the widow mothers seemingly because of the negative attitude on exclusive breastfeeding that was posted on them by their former husband. The polygamous mothers have reported a high rate of exclusive breastfeeding and this could have been attributed by the social network with the co-wife's who might have exclusively breastfed successfully before.

The single mothers reporting to have exclusively breastfed could be because of the freedom of choice they have. This finding is supported by argument of Charlottes, 2009, who report that low levels of involvement by fathers and other community members is another reason for not taking the advice from health centre's easily. The finding is further supported by the argument of US Department of health and humanities 2011who argued that in Africa, many families, fathers play a strong role in the decision of whether to breastfeed. Fathers may be opposed to breastfeeding because of concerns about what their role would be in feeding, whether they would be able to bond with their infant if they were personally unable to feed the baby, and how the mother would be able to accomplish household responsibilities if she breastfed. Studies of African American families in which education on breastfeeding was directed at the father found a 20 percent increase in breastfeeding rates, indicating that paternal influences on maternal feeding practices are critically important in early decision making about breastfeeding. The absence of men and youth groups from breast feeding promotion activities has been identified as a contributing factor to the low numbers of women who breastfeed $^{[14]}$

The finding on marital status is in contrast to the one done in Kigoma Tanzania which reveals no association in marital status with exclusive breast feeding. (Tiras, 2010).It is also in contrast to the one done in Nigeria which shows that marital status does not affect the strength of the observed association ( $\mathrm{P}>0.05$ ) (Comfort, MPH (Class of 2011). The contrast could have been influenced by the cultural differences across the communities among which the studies were done and the design of the study.

\subsection{Personal Characteristics Associated with Exclusive Breast Feeding Practices among Lactating Mothers in Siaya County}

ANC attendance in this study had no association with exclusive breast feeding. This study agrees with the study done by Alemayehu, et al reported that there is no association with ANC and exclusive breastfeeding.

This study on ANC attendance disagrees with the study done in Nigeria by Comfortin 2011, which reported that there is a strong positive association between exclusive breast-feeding and ANC attendance. It also disagrees with the study done by Sharma in India on 2006, who revealed that there is an association between exclusive breast feeding and ANC attendance.

This finding reports that there is no association between health facility delivery and exclusive breast feeding. The study contrasts with the report byBFHI - BMC Public Health 2011, which reported that mothers who delivered at home were more likely to introduce complementary food earlier than those who delivered in a health facility. The report further states that the results are similar to those observed in Switzerland, Italy and Brazil. This contrast could have been contributed by difference in study background and culture.

It also disagrees with Tanzania Demographic and Health 
Survey (TDHS) 2004/05 report, which also report that there is an association between exclusive breastfeeding and health facility delivery. The differences in the findings may be due to either the time period the study was done or the sampling size of the study.

The findings on the initiation of the breast milk to the baby, state that there is an association between the time of putting the child on breast milk and exclusive breast feeding. This support the argument by CDC guide to breast feeding intervention 2010, which argues that breastfeeding in the first hours and days of life significantly influence an infant's later feeding.

The findings on counselling on breast feeding mothers show that there is no association with exclusive beast feeding. There is also no association on the referral of food by prescription. These findings on ANC services, health facility delivery, counselling and referral of food by prescription, proposed the argument of Surtherland, 2009, which state that in Africa, as noted, clinics and health centres advice mothers to breastfeed exclusively for at least six months of their babies lives, however, when mothers arrived home, several others factors come into play. First, in the African context, mothers are usually not the sole decision makers when it comes to their children. Grandmothers play an important role in the mothers and infants lives and are said to have a strong influence over what mothers feed their babies. In Burkina Faso, for example, grandmothers are reported not to approve of exclusive breastfeeding (3). According toSawoudogo, a nurse and Director of the village clinic in Zincko, Kaya health district, $100 \mathrm{~km}$ northeast of the capital, Ouagadougou, grandparents are the "real" decision makers when it comes to child care. "Children do not belong to only their parents in African society ${ }^{[9]}$.

\section{Conclusions}

Demographic factors; that are age category and marital status were associated with exclusive breast feeding practices among lactating mothers in Siaya County. Among the age category, older mothers breastfeed more than younger mothers. Among the marital status, polygamous mothers' breastfeed more than monogamous mothers and therefore, peer influence encourage mothers to breastfeed more. Single mothers' breastfeed more than married mothers.

Personal characteristics; that is first initiation of breast milk within the first hours after birth is associated with exclusive breast feeding practices among lactating mothers in Siaya County.

\section{REFERENCES}

[1] Alemayehu, T,. Haidar, J., \&Habte, D., Determinants of breastfeeding practices in Ethiopia, Ethiop. J.Health Dev, 2009.

[2] Chidozie E Mbada, Adekemi EOlowookere, Joel O Faronbi, Folasade C Oyinlola, Aromolaran, Funmilola A Faremi, Abiola O Ogundele, Taofeek O Awotidebe, Adepeju A Ojo and Oluwakemi A Augustine. BioMed Central. BMC Research notes 2013.

[3] CHNRI (2005) Successfully Scaling up Exclusive Breastfeeding:Lessons from Madagascar A Research Brief by the Child Health and Nutrition Research Initiative. An intitative of the Global Forum for Health Researcg. 2000.

[4] Dr. Deeksha Sharma. Assement of status of infant and young child feeding. District: Chamoli (State of Uttarakhand). Department of Women Empowerment and child Development, Uttarakhand, breadfeeding Promotion Network of India. 2006.

[5] ENBS. Ethiopia Demography and Health Survey. 2005.

[6] Jones, G., RW Steketee, RE Black, ZA Bhutta, SS MorrisHow many child death can we prevent this year?, Lancet, US National institute of health (2003).

[7] Mahajan Nitrin, Gujrathi Amit, Kasbe Abhiram, Dhakne Supriya. Does utilization pattern of antenatal care and early neonatal practices improved by close supervision and support intervention among primigravidae in the tribal area?Community based intervention study. IJIMS. International Journal of interdiscipline and multidisciplinary studies. 2014.

[8] Robert E Black, Saul S Morris, Jennifer Bryce. Where and why are 10 milllion children dying every year?. Lancet. Child Survival 1.2003.

[9] Sutherland, C, Exclusive breastfeeding within a social context -Reflecting on the current situation in Africa. Consultancy Africa Intelligence.2009.

[10] Tan , K, T.Factors associated with exclusive breastfeeding among infants under six month of age in Peniusular Malaysia, BioMed Central Ltd, International Breast feeding journal, 2011.

[11] Tewodros Alemayehu, Jemal Haidar, Dereje Habte. Determinants of exclusive breastfeeding practices in Ethiopia. School of Public Health Addis Ababa University, Medical Faculty. Ethiopia J. Health Dev. 2009.

[12] Tiras Eshton Nkala and Sia Emmanueli Msuya. Prevalence and predictors of exclusive breast feeding among women in Kigoma region, Western Tanzania: a community based cross - sectional study. BioMed Central Ltd. International Breast feeding journal 2011.

[13] TNBS. Tanzania Demography and Health Survey, 2004/ 2005.

[14] U.S. Department of Health and Human Services. The Surgeon General's Call to Action to Support Breastfeeding. Washington, DC: U.S. Department of Health and Human Services, Office of the Surgeon General; 2011.

[15] WHO Reproductive Health library, Geneva: World Health Organisation 2008. 